\title{
REVIEW
}

\section{Systemic Treatment of Pediatric Psoriasis: A Review}

Maddalena Napolitano · Matteo Megna · Anna Balato •

Fabio Ayala $\cdot$ Serena Lembo · Alessia Villani $\cdot$ Nicola Balato

Received: February 29, 2016 / Published online: April 16, 2016

(c) The Author(s) 2016. This article is published with open access at Springerlink.com

\section{ABSTRACT}

Psoriasis is a chronic, immune-mediated, inflammatory skin disease, affecting $1-3 \%$ of the white population. Although the existence of two psoriasis incidence peaks has been suggested (one in adolescence before 20 years of age and another in adulthood), its onset may occur at any age, including childhood and adolescence, in which the incidence is now estimated at 40.8 per 100,000 . As for adult psoriasis, pediatric psoriasis has recently been associated with obesity, metabolic syndrome, increased waist circumference percentiles and metabolic laboratory abnormalities, warranting early monitoring and lifestyle modifications. In

Enhanced content To view enhanced content for this article go to www.medengine.com/Redeem/15B4F0600 F2B8B8E.

M. Napolitano and M. Megna contributed equally to this study.

M. Napolitano · M. Megna $(\bowtie) \cdot$ A. Balato .

F. Ayala $\cdot$ S. Lembo $\cdot$ A. Villani $\cdot$ N. Balato

Department of Dermatology, University of Naples

Federico II, Naples, Italy

e-mail: mat24@libero.it addition, due to psoriasis' chronic nature and frequently occurring relapses, psoriatic patients tend to have an impaired quality of life, often requiring long-term treatment. Therefore, education of both pediatric patients and their parents is essential to successful and safe disease management. Given the lack of officially approved therapies, the very limited evidence-based data from randomized controlled trials, and the absence of standardized guidelines, to date, pediatric psoriasis treatment is primarily based on published case reports, case series, guidelines for adult psoriasis, expert opinions and experience with these drugs in other pediatric disorders coming from the disciplines of rheumatology, gastroenterology and oncology. This review focuses on the use of systemic treatments in pediatric psoriasis and their specific features, analyzing the few literature evidences available, expanding the treatment repertoire and guiding dermatologists in better managing of recalcitrant pediatric psoriasis.

Keywords: Biologics; Childhood; Pediatric psoriasis; Systemic treatments 


\section{INTRODUCTION}

Psoriasis is a chronic inflammatory skin disease that affects $1-3 \%$ of the population [1]. This multifactorial papulosquamous disorder is also believed to be common in pediatrics [2]. Particularly, psoriasis is reported to affect $0.5-1 \%$ of children in Europe [3]. Moreover, the incidence of pediatric psoriasis is significantly increased over time, being now estimated at 40.8 per 100,000 with a median age onset between 7 and 10 years [4, 5]. Furthermore, a few prevalence surveys have demonstrated that about one-third of psoriasis patients sometimes develop their symptoms during childhood, although some of these may not be diagnosed until adulthood [6, 7]. Since children differ from adults, specific guidelines underlining clinical pictures and management are needed to support early intervention, which is also fundamental to achieving psychological comfort and preventing the appearance of comorbidities, apart from controlling and limiting the burden of the disease [8]. However, there are currently no international standardized guidelines for medical treatment of pediatric psoriasis. Indeed, to date, treatment is primarily based on published case reports, case series, guidelines for adult psoriasis, expert opinions and experience with these drugs in other pediatric disorders. As a consequence, most anti-psoriatic drugs, especially systemic ones, are often used off label [2]. This review focuses on the use of systemic treatments in pediatric psoriasis and their specific and peculiar features analyzing the few literature evidences and studies regarding systemic therapy in childhood psoriasis management.

\section{METHODS}

We searched for English-language literature regarding systemic treatments in pediatric psoriasis in the following databases through 7 February 2016: PubMed, Embase, The Cochrane Library, Google Scholar, Scopus and EBSCO. The following key words were used: "pediatric psoriasis," "childhood psoriasis," "systemic therapy," "systemic treatments," "psoriasis," "childhood," "children," "infancy," "cyclosporine," "methotrexate," "acitretin," "etretinate," "fumaric acid esters," "biologics," "adalimumab," "etanercept," "infliximab" and "ustekinumab." This article reviews especially newer data to address the issues that surround pediatric psoriasis and to provide an update on its systemic treatments. All the evidence was evaluated by the authors, who then combined this with clinical experience of everyday practice in an effort to provide a complete review of the management of psoriasis in childhood.

This article is based on previously conducted studies and does not involve any new studies of human or animal subjects performed by any of the authors.

\section{MANAGEMENT OF PEDIATRIC PSORIASIS: SYSTEMIC THERAPY}

The management of pediatric psoriasis is a complicated and intriguing task. Standardized guidelines for the treatment of children with psoriasis are lacking, although certain published psoriasis guidelines for adults address several issues that concern younger populations $[9,10]$. Both available systemic therapies for pediatric psoriasis and randomized controlled trials supporting their use are limited, so that physicians have to rely on data from case reports and case series from the field of dermatology as well as from the application of the same drugs but for rheumatologic or gastroenterological pediatric conditions. Given 
Table 1 General approach to pediatric psoriasis treatment

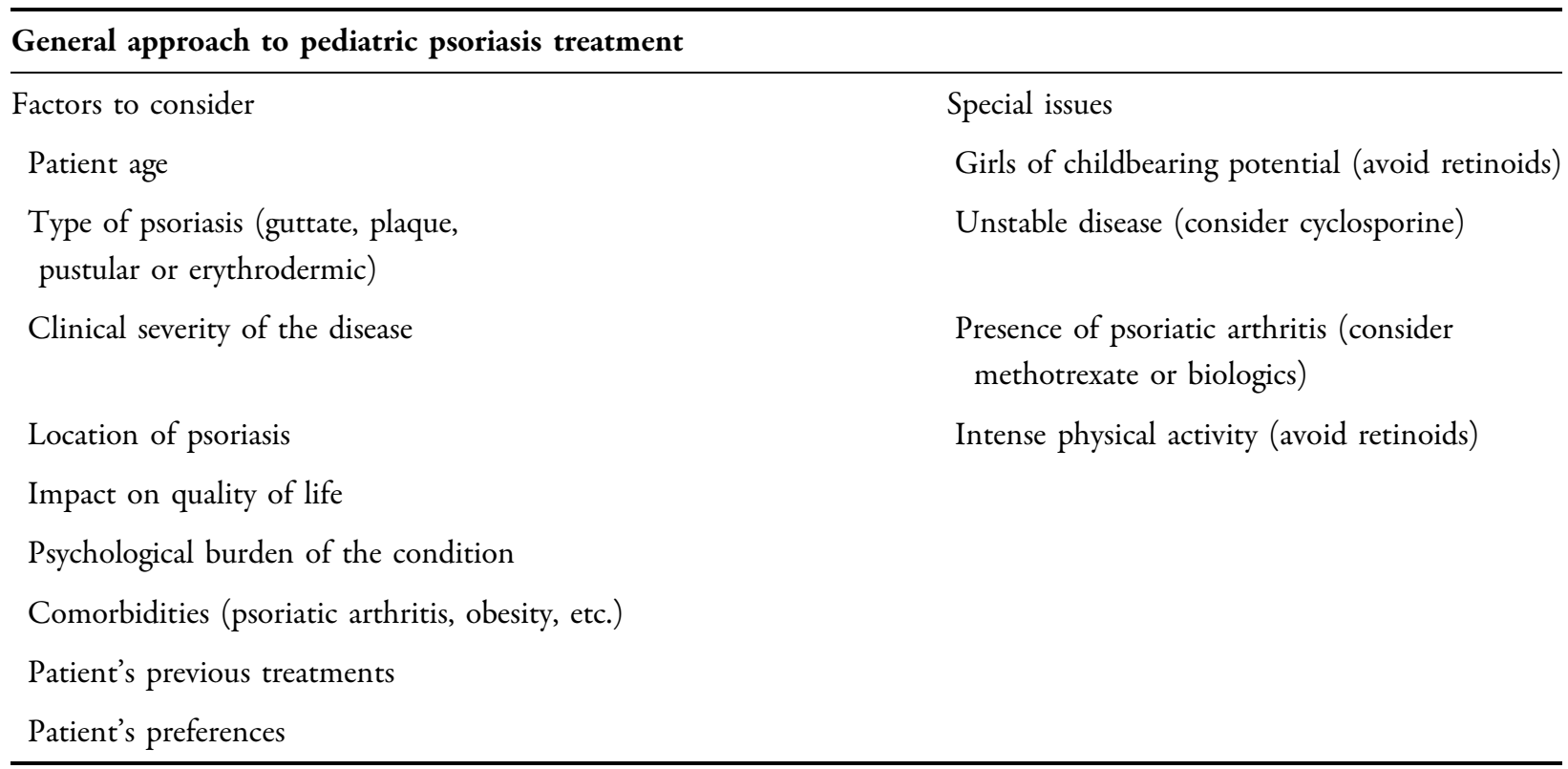

the lack of guidelines, a general approach should be performed (Table 1): the choice of the most appropriate treatment should be influenced by several factors such as patient age, clinical severity of the disease, the impact on quality of life, the psychological burden of the condition, the presence of comorbidities (psoriatic arthritis, obesity, etc.), as well as the patient's previous treatments and preferences $[2,11]$.

\section{PHOTOTHERAPY}

Children with psoriasis typically respond very well to treatment with phototherapy, which is considered an appropriate treatment in case of debilitating palmo-plantar psoriasis, diffuse psoriasis involving more than $15-20 \%$ of the body surface area, refractory plaque/ guttate/pustular psoriasis or patients who cannot receive systemic drugs for their moderate to severe psoriasis [12]. There are three main alternatives: broadband ultraviolet B (BB-UVB, 280-320 nm), narrowband (NB)-UVB
(311-313 nm) and UVA (320-400 nm). They inhibit DNA synthesis and keratinocyte proliferation and induce apoptosis of $\mathrm{T}$ lymphocytes and production of anti-inflammatory mediators [13]. BB-UVB comprises the most active portion of sunlight radiation and produces excellent responses in case of guttate psoriasis. NB-UVB is less erythemogenic than BB-UVB and has been shown to be effective especially for guttate or thin plaque disease; it is now considered the first-line phototherapy, because of its association with milder side effects $[14,15]$. Short-term side effects from UVB phototherapy have been well described also in pediatric population and comprise dry skin, itch, erythema, blistering and herpes virus activation [16]. On the other hand, long-term side effects, mainly consisting of premature photoaging and carcinogenesis, are not well documented in children $[15,16]$. However, the cumulative effect of UVB phototherapy and chronic sun exposure has been linked to skin cancer. Thus, long-term follow-up of psoriatic children who attend 
phototherapy is necessary to clarify the associations with adverse effects. The cumulative UVB dose and cancer risk can be reduced combining phototherapy with systemic or topical treatment, such as acitretin and calcipotriol, respectively [16-18]. NB-UVB is considered the most efficacious and safe type of phototherapy in children [19]. In 2011, a retrospective study in pediatric psoriasis patients showed complete clearance in 51\% and a good response (at least 75\% improvement) in $41 \%$ of the subjects through a mean treatment duration of 3.3 months [20]. Recently, Wong et al. performed a retrospective study on 12 pediatric psoriasis patients treated with NB-UVB, also performing a thorough review of the literature, and concluded that this type of phototherapy is a safe and effective treatment for childhood psoriasis and should be considered in children with suboptimal response to topical therapy [21]. Indeed, there are several published case series in the literature attesting to the efficacy of UVB phototherapy, in particular NB-UVB phototherapy, in treating plaque and guttate psoriasis in children aged 2-18 years, with the majority of patients achieving a moderate to significant response or almost complete to total remission over an average of 25-34 treatments, with one study reporting a mean duration of remission of 8 months [16, 20, 22-25]. However, the potential early side effect, together with the need of recurrent medical visits and the difficulty in remaining within UV chambers, often make phototherapy unsuitable for small children and infants; also the logistics and frequency of appointments could be also an issue for patients' parents [15, 17]. Regarding photochemotherapy, it acts through UVA and the photosensitizing psoralen (PUVA) use. PUVA therapy is usually contraindicated in children younger than 12 years also because of their ingestion-related toxicity, including nausea and vomiting, headaches, ocular and hepatic toxicity, generalized photosensitization needing photoprotection for $24 \mathrm{~h}$, the possibility of burning and long-term risk of skin cancer [12, 26]. Indeed, PUVA is now rarely used in children because of long-term toxicity; topical PUVA treatments are generally preferred [15].

\section{NON-BIOLOGIC SYSTEMIC DRUGS}

Severe or refractory plaque, pustular or erythrodermic psoriasis and psoriatic arthritis (PsA) require systemic drugs. As in adults, non-biologic systemic drugs used for pediatric psoriasis (Table 2) include: acitretin, a non-immunosuppressing retinoid, and the immunosuppressants methotrexate (MTX) and cyclosporine (CsA). None of them is FDA labeled for psoriasis in children because of the lack of randomized controlled trials in this age category [12]. Data on benefits and risks of these therapies for psoriasis mainly come from long-term use in pediatric patient affected by other diseases such as ichthyoses (acitretin), juvenile rheumatoid arthritis (MTX) and organ transplantation (CsA) [12]. Due to the risk of adverse reactions and other potential adverse effects, use of systemic medications for the treatment of psoriasis in children is generally reserved for recalcitrant disease, severe and/or diffuse disease, or the presence of juvenile PsA. Systemic agents may be combined with use of topical agents and/or phototherapy in order to enhance efficacy and reduce the risk of adverse effects [27]. A very recent French multicenter retrospective study collecting data from 2000 to 2014 regarding 154 children with moderate to severe psoriasis showed that acitretin was the most frequently used therapy (54.4\%) and was mainly used as first-line treatment (76.6\%) [28]. The authors also highlighted the favorable 
Table 2 Overview of non-biologic systemic treatments in pediatric psoriasis

\begin{tabular}{|c|c|c|c|}
\hline Drug & Dosage & Side effects & Laboratory monitoring \\
\hline Cyclosporine & $\begin{array}{l}1.5 \text { to } 5 \mathrm{mg} / \\
\mathrm{kg} / \text { day }\end{array}$ & $\begin{array}{l}\text { Renal toxicity, hypertension nausea, } \\
\text { diarrhea, myalgias, headache, } \\
\text { electrolyte abnormalities } \\
\text { (hyperkalemia and hypomagnesemia), } \\
\text { hyperlipidemia, hypertrichosis, and } \\
\text { gingival hyperplasia }\end{array}$ & $\begin{array}{l}\text { Blood count, creatinine, urea, } \\
\text { cholesterol, triglycerides, } \\
\text { electrolytes }\end{array}$ \\
\hline Fumaric acid esters & $\leq 720 \mathrm{mg} /$ day & $\begin{array}{l}\text { Gastrointestinal complaints, flushes, } \\
\text { hematological abnormalities } \\
\text { (lymphocytopenia and eosinophilia) }\end{array}$ & Blood count, liver enzymes \\
\hline Methotrexate & $\begin{array}{l}0.2 \text { to } 0.7 \mathrm{mg} / \\
\mathrm{kg} / \text { week }\end{array}$ & $\begin{array}{l}\text { Nausea, vomiting, fatigue, hematological } \\
\text { abnormalities, hepatotoxicity, } \\
\text { pulmonary toxicity }\end{array}$ & Blood count, liver enzymes \\
\hline Retinoids & $\begin{array}{l}\leq 0.5 \text { to } 1 \mathrm{mg} / \\
\mathrm{kg} / \text { day }\end{array}$ & $\begin{array}{l}\text { Cheilitis, xerosis, epistaxis and increase of } \\
\text { serum lipids and hepatic enzymes } \\
\text { Skeletal abnormalities } \\
\text { Teratogenicity }\end{array}$ & $\begin{array}{l}\text { Serum lipids and liver enzymes } \\
\text { Radiographs of the spine }\end{array}$ \\
\hline
\end{tabular}

safety profile of systemic treatments in psoriatic children reporting side effects in only $33.7 \%$ subjects with most of them being benign and not presenting influence on treatment duration. Based on this study, acitretin, MTX and CsA may be considered as first-line therapy for childhood psoriasis with an acceptable efficacy and few adverse effects, with acitretin seeming efficient on plaque, pustular and palmoplantar psoriasis, MTX on plaque and guttate psoriasis, and CsA on erythrodermic and palmoplantar psoriasis [28]. However, the choice of agent remains a challenge because of the limited number of clinical trials and lack of guidelines in this age group. On the other hand, also other non-biologic systemic treatments for pediatric psoriasis have been described in the literature even if their use seems to be limited in selected countries (Germany and The Netherlands for fumarates and Japan for etretinate). However, most of the systemic treatments are not approved to use in children and are used off label [29]. Therefore, daily practice clinical decision making can be complicated and challenging.

\section{Acitretin}

Acitretin is a second-generation aromatic retinoid suitable for children with generalized flares and pustular psoriasis as intermittent rescue therapy and in case of pustular, erythrodermic or severe plaque psoriasis of older children as long-term therapy [30]. This drug can also be associated with topicals and NB-UVB phototherapy [18]. However, no randomized controlled trials exist for this drug in childhood psoriasis [31]. Oral retinoids are safe in children, as verified by long-term follow-up of patients with keratinization diseases, but always require monitoring [32].

Treatment dosages should be $\leq 0.5$ to $1 \mathrm{mg} /$ $\mathrm{kg} /$ day to limit the appearance of toxicity. 
Common adverse events include cheilitis, xerosis and pruritus, epistaxis and an increase of serum lipids and hepatic enzymes, which do not usually lead to treatment discontinuation [33]. Teratogenicity and bone alterations represent the most serious adverse events. Young females of childbearing potential should not use acitrenin or combine its use with oral contraceptive therapy, avoiding pregnancy for 3 years after drug withdrawal [30]. Effects on bone seem to be associated only with long-term use of high acitretin doses, whereas the link between radiologic modifications of the skeletal system and long-term use of low acitretin doses is still unclear [34, 35]. No correlation between skeletal abnormalities and dose or duration of treatment has been shown, and no evidence of a link between hyperostosis or increased risk of osteoporosis and prolonged retinoid therapy has been reported [36, 37]. Nevertheless, bone and spine radiology together with regular growth parameter assessment should be applied in children on long-term retinoid therapy [12]. Case reports and small case series showed acitretin use in childhood psoriasis either as monotherapy or in combination with corticosteroids, MTX, NB-UVB phototherapy or PUVA, especially for the treatment of pustular psoriasis and erythrodermic psoriasis. Although clinical improvement was generally reported after 2-3 months of therapy, recurrence of disease necessitating intermittent therapy appeared to be common. However, overall the use of acitretin was well tolerated, and adverse effects were minimal [18, 38-46].

\section{Methotrexate}

Methotrexate is an antimetabolite that modulates the immune system and the inflammatory processes. Its anti-psoriatic use dates back to the 1950s, and its prescription for severe psoriasis is still the most frequent worldwide [47]. MTX is considered the systemic treatment of choice for children with moderate-to-severe plaque psoriasis [31]. However, its use in childhood is also appropriate for PsA, extensive, recalcitrant, severe or disabling psoriasis, and erythrodermic or generalized pustular disease resistant to topical and phototherapy [12].

In children, MTX advantages include the efficacy and weekly oral dose $(0.2-0.7 \mathrm{mg} / \mathrm{kg} /$ week) [48]. Dose escalations of $1.25-5 \mathrm{mg} /$ week until the achievement of clinical benefits, followed by a slow taper to a maintenance dosage, are advised [12]. However, to date there is no consensus about the MTX dosing regimen and treatment duration in pediatric psoriasis also because the considerable reported interindividual variability and low intraindividual variability of its pharmacokinetics support a role for therapeutic monitoring and dose individualization at the start of pharmacotherapy [49]. As soon as therapeutic control has been achieved, it is recommended to taper the dose to an effective but lower maintenance dose to reduce side effects [50]. Parenterally administered MTX is only used in case of unsuccessful oral therapy or gastrointestinal side effects [17]. This drug is associated with many potential side effects, mainly nausea, vomiting, fatigue, hematological abnormalities, hepatotoxicity, pulmonary toxicity and drug interactions, which need clinico-laboratory monitoring [51]. Clinical experience usually reports minor short-term side effects with MTX use [31]. However, since the total cumulative dose of MTX is linked to hepatotoxicity, it should not be used if children require many years of systemic therapy [17]. Hepatotoxicity and liver 
fibrosis are much rarer in children than in adults, and expert opinion suggests that biopsy is not required unless there is clinical and/or laboratory evidence of significant abnormality or cumulative doses exceeding $1.5 \mathrm{~g}[19,52]$. Generally, MTX-associated short- and long-term side effects are less frequent and severe in psoriatic children than in adults, probably due to the low frequency of concomitant medications and comorbidities at the pediatric age [12]. Folic acid is routinely administered to improve tolerability and decrease the appearance of nausea, macrocytic anemia, pancytopenia and hypertransaminasemia even if the optimal dose and timing of its administration are still unclear [29, 53-55]. Indeed, some authors prescribe folic acid 2 days after every MTX dose, while others recommend daily except on the day of MTX therapy [52]. A recent analysis of a prospective registry demonstrated the safety and efficacy of oral and/or subcutaneous MTX in 25 children with plaque psoriasis [53]. Based on the available evidence, MTX is considered to be the systemic treatment of choice in children with moderate to severe plaque psoriasis and its variants [56-58]. A recent subset analysis of prospectively collected data extracted from the Child-CAPTURE registry, a single-center, longitudinal, long-term, observational daily practice cohort of pediatric psoriasis patients, showed that MTX presents a positive effect on the psoriasis area and severity index (PASI) scores, improves quality of life and has a reasonable safety profile [57]. Particularly, a maximum dose of MTX between 0.14 and $0.63 \mathrm{mg} / \mathrm{kg}$ once weekly was prescribed in 25 children with PASI75 being achieved in $4.3 \%$ and $33.3 \%$ of patients at week 12 and 24 , as well as $40 \%$ and $28.6 \%$ at week 36 and 48 , respectively. Treatment also led to a significant decrease in the Children's Dermatology Life
Quality Index (from 9.0 to 3.8 at week 24) without severe adverse events [most reported adverse events were severe nausea (20\%), infections requiring antibiotics (20\%) and tiredness (16\%)] [57]. There are also several case reports and small case series demonstrating the benefits of MTX in the treatment of recalcitrant plaque psoriasis, erythrodermic psoriasis, pustular psoriasis and severe palmoplantar psoriasis in children as young as 2 years of age [55, 59-66]. Significant clinical improvement was noted after as little as 5 weeks of therapy, and clinical remissions were reported that ranged in duration from 1.5 months to 3 years. Nausea and vomiting were commonly reported adverse effects, and transient elevations in liver enzymes were also seen.

\section{Cyclosporine}

Cyclosporine is an immunosuppressant that inhibits IL-2 and the function of $T$ lymphocytes. The FDA approved its use in immunocompetent adults with severe, recalcitrant psoriasis and in pediatric transplant patients with more than 6 months of age [12]. However, this drug is also useful in severe psoriasis, including pustular and erythrodermic variants of the disease, in case of ineffective previous treatment and in short-term crisis management [67-69]. Indeed, case series and reports support the use of CsA in the treatment of recalcitrant plaque and pustular juvenile psoriasis at doses of $1.5-5 \mathrm{mg} / \mathrm{kg} /$ day for 6 weeks-2 years [67-71]. CsA effects can be clinically observed in 4-8 weeks so that it is considered the ideal drug for the control of unstable disease because of its rapid onset of action [11]. With the aim of increasing efficacy and decreasing toxicity, the drug can be associated with topical and other 
systemic treatments [72]. The CsA dose, which usually ranges from 3 to $5.0 \mathrm{mg} / \mathrm{kg} /$ day, influences the rate of improvement and should be progressively tapered to the lowest one needed to control disease [69]. CsA may present pharmacokinetic differences between children and adults: in children oral absorption may be lower, clearance is more rapid, and volume distribution at a steady state is greater [71]. Therefore, cases of childhood psoriasis may require higher dosages of CsA, or doses should be administered three times per day [71]. In general, treatment duration should not exceed 12 months, and close monitoring of renal function is mandatory. Indeed, the risk of renal toxicity, hypertension and immunosuppression limits CsA use; thus, laboratory and blood pressure monitoring before and during treatment is essential [73]. Other adverse events include nausea, diarrhea, myalgias, headache, electrolyte abnormalities (hyperkalemia and hypomagnesemia), hyperlipidemia, hypertrichosis and gingival hyperplasia. A matter of concern, also in children, is the risk of malignancies, in particular skin cancer and lymphoproliferative diseases; however, this risk seems to be negligible using doses $\leq 5 \mathrm{mg} / \mathrm{kg} /$ day and avoiding the association of CsA with other immunosuppressive treatments [74]. Indeed, although CsA can be combined with several topical or systemic agents (acitretin), in order to reduce the total dose and duration of the two combined agents [19], the association with NB-UVB is usually avoided because of the potential long-term risk of developing nonmelanoma skin cancer [52]. Several case reports and small cases series attesting to the use of CsA, either as monotherapy or in combination with topical therapy or corticosteroids, in the treatment of pediatric pustular psoriasis, erythrodermic psoriasis, recalcitrant plaque psoriasis and palmoplantar psoriasis in children as young as 11 months of age have been published in the literature with clinical improvement typically noticed after 2-3 months of therapy [39, 67-71, 75, 76]. Recently, a case series of 22 patients of childhood psoriasis treated with CsA was performed through a retrospective analysis of patient records from 2000 to 2009 at the Department of Dermatology and Venereology of the University School of Medicine, Bursa, Turkey [77]. The mean therapeutic dosage of CsA was $3.47 \pm 0.62 \mathrm{mg} / \mathrm{kg} /$ day with a mean treatment duration of $5.68 \pm 3.29$ months. Seventeen of 22 patients $(77.3 \%)$ were found to be excellent responders presenting with a median time to total clearance of the lesions of 4.0 weeks [77]. Moreover, a recent Italian multicenter retrospective analysis of 38 psoriatic children showed CsA to be an effective and well-tolerated treatment. Particularly, they reported a median maintenance dosage per day of $3.2 \mathrm{mg} / \mathrm{kg}$ and achievement of an improvement from baseline of $\geq 75 \%$ in PASI at week 16 by $15 / 38$ patients (39.4\%). On the other hand, $8 / 38$ patients (21.05\%) discontinued the treatment because of laboratory anomalies or adverse events so that the authors drew the conclusion that cyclosporine, when carefully monitored, may represent a therapeutic alternative to the currently used systemic immunosuppressive agents for severe childhood psoriasis [78].

\section{Etretinate}

Etretinate is an aromatic retinoic acid derivative like acitretin, which is its free acid. Etretinate acts by inhibiting hyperkeratinization and cell differentiation. Nowadays, etretinate use is generally replaced by acitretin since the latter shows a more favorable pharmacokinetic profile 
due to its shorter elimination half-life with respect to etretinate. Indeed, etretinate presents a deep storage compartment with a very extended elimination half-life with detectable drug plasma levels for at least 3-4 months after discontinuation of treatment [79]. Therefore, the choice of using etretinate rather than acitretin is uncommon and usually characterizes Asian countries (Japan above all) where acitretin use is not approved or reimbursable by health insurances [80]. Etretinate use is described in about 14 pediatric patients with pustular psoriasis. Dosage ranged from 0.25 to $1.5 \mathrm{mg} / \mathrm{kg} /$ day, showing remarkable or excellent improvement in most cases [43, 80-84]. Side effects included xerosis, skin fragility and transient elevations of liver enzymes, lactic dehydrogenase, and cholesterol and triglyceride levels. Apart from teratogenicity, for which reason it should be not used in young females of childbearing potential, the major problem in treating children with etretinate is the risk of skeletal toxicity; therefore, radiographs of the spine and bone age should be periodically monitored as in the case of acitretin, given their similarities [85].

\section{Fumaric Acid Esters}

Fumaric acid esters (FAEs) are small molecules with a broad range of immunomodulatory effects [86]. FAE use was recently described in 14 pediatric patients with plaque psoriasis. Mean treatment duration was 48.6 weeks with daily doses varying between 180 and $1200 \mathrm{mg}$, showing improvements in $64.3 \%$ of subjects. Most common adverse events were gastrointestinal complaints (92.9\%) and flushes (71.4\%) followed by lymphocytopenia (45.5\%) and eosinophilia (36.4\%), being usually mild and transient [87]. Similar effectiveness and safety results were also previously shown by Balak et al. in a cohort of 14 pediatric psoriasis patients analyzed retrospectively [88]. Moreover, data obtained by a study analyzing 127 childhood or adolescence psoriatic subjects suggests that long-term FAE therapy may be effective and safe showing also that the dosage recommended for adults is essentially effective for children and adolescents and similarly well tolerated [89]. FAEs are considered a valuable alternative option in pediatric psoriatic patients when systemic treatment is needed, especially in Dutch and German countries where it is usually used [90]. Indeed, FAEs are a recommended first-line therapy in the German S3 guideline for the treatment of adult psoriasis, but its use still remains an off-label treatment in this age group [91].

\section{BIOLOGIC DRUGS}

Biologic drugs are a novel class of pharmacological agents engineered to target specific mediators of inflammation. During the past several years, multiple randomized controlled studies have confirmed the efficacy of targeted therapy with tumor necrosis factor (TNF)- $\alpha$ antagonists (etanercept, infliximab and adalimumab) or interleukin (IL)12/IL23 pathway inhibitor (ustekinumab) for the treatment of severe and/or recalcitrant psoriasis and PsA in adults [92]. Nevertheless, evidence supporting the role of biologic agents in the treatment of pediatric psoriasis is lacking. Indeed, the exact role of biologics in the treatment of pediatric psoriasis remains undefined but is evolving. Biologics are an attractive option for use in children in part because they offer more convenient dosing regimens and less frequent laboratory monitoring than other systemic agents. Future research is needed to determine the efficacy, pediatric dosing and long-term safety of these agents (Table 3). 
Table 3 Overview of biologic treatments in pediatric psoriasis

\begin{tabular}{|c|c|c|c|}
\hline Drug & Dosage & Side effects & Laboratory monitoring \\
\hline Etanercept & $\begin{array}{l}0.8 \mathrm{mg} / \mathrm{kg} / \text { week or } 0.4 \mathrm{mg} / \mathrm{kg} \\
\text { twice weekly }\end{array}$ & $\begin{array}{l}\text { Increased risk of infection, } \\
\text { injection-site reaction, anaphylaxis, } \\
\text { development of anti-nuclear } \\
\text { antibodies, lupus-like syndrome, } \\
\text { pancytopenia }\end{array}$ & $\begin{array}{l}\text { Blood count, liver enzymes, } \\
\text { PPD test annually }\end{array}$ \\
\hline Infliximab & $\begin{array}{l}3-5 \mathrm{mg} / \mathrm{kg} \text { at weeks } 0,2 \text { and } 6 \\
\text { then every } 8 \text { weeks }\end{array}$ & $\begin{array}{l}\text { Increased risk of infection, acute } \\
\text { infusion reaction, delayed } \\
\text { hypersensitivity reaction, anaphylaxis, } \\
\text { development of anti-nuclear } \\
\text { antibodies, lupus-like syndrome, } \\
\text { pancytopenia } \\
\text { New onset or exacerbation of } \\
\text { demyelinating disorder }\end{array}$ & $\begin{array}{l}\text { Blood count, liver enzymes } \\
\text { more frequently than } \\
\text { with other TNF-blockers, } \\
\text { PPD test annually }\end{array}$ \\
\hline Adalimumab & $\begin{array}{l}0.8 \mathrm{mg} / \mathrm{kg} \text { (up to maximum } 40 \mathrm{mg} \\
\text { in total) at week } 0 \text { and } 1 \text { and } \\
\text { then every } 2 \text { weeks }\end{array}$ & $\begin{array}{l}\text { Increased risk of infection, } \\
\text { injection-site reaction, anaphylaxis, } \\
\text { development of anti-nuclear } \\
\text { antibodies, lupus-like syndrome, } \\
\text { pancytopenia } \\
\text { New onset or exacerbation of } \\
\text { demyelinating disorder }\end{array}$ & $\begin{array}{l}\text { Blood count, liver enzymes, } \\
\text { PPD test annually }\end{array}$ \\
\hline Ustekinumab & $\begin{array}{l}0.750 \mathrm{mg} / \mathrm{kg} \text { (for patients } \leq 60 \mathrm{~kg} \text {; } \\
\text { otherwise same dosage for } \\
\text { adults) at week } 0 \text { and } 4 \text { then } \\
\text { every } 12 \text { weeks }\end{array}$ & $\begin{array}{l}\text { No specific adverse effects reported in } \\
\text { clinical trials }\end{array}$ & $\begin{array}{l}\text { Blood count, liver enzymes, } \\
\text { PPD test annually }\end{array}$ \\
\hline
\end{tabular}

\section{Etanercept}

Etanercept has the majority of literature papers recommending its use for childhood psoriasis [93-95]. It is a soluble tumor necrosis factor receptor fusion protein that reversibly binds to tumor necrosis factor, administered twice weekly by subcutaneous injection. In children, it has been FDA approved only for the treatment of juvenile idiopathic arthritis (JIA) [96], although, in 2009, the European Commission approved it for the treatment of children $\geq 6$ years old with chronic severe plaque psoriasis intolerant or resistant to non-biologic systemic therapies, also including phototherapy [97]. The best data for its efficacy and safety in pediatric psoriasis come from a randomized, double-blind phase III clinical trial in which 211 pediatric patients aged 4-16 years with moderate to severe plaque psoriasis were treated with etanercept $(0.8 \mathrm{mg} / \mathrm{kg} /$ week $)$ over 48 weeks. No opportunistic infections (including tuberculosis), demyelinating diseases, tumors or deaths were found [94]. Moreover, an open-label extension period of this study confirmed its efficacy and safety by evaluating 69 patients who remained in the study for up to 264 weeks, achieving the clear/ almost clear status [98]. Upper respiratory tract infections, pharyngitis, injection site reactions 
and headaches were the most frequent adverse events that occurred during this extension period, and no new safety concerns were observed with long-term treatment in this patients population [98]. These data were confirmed by Beikert et al. in eight children with severe psoriasis who failed to respond to other therapy: within 12 weeks, six patients reached a PASI reduction of $75 \%$. Two patients stopped use at week 12 because of ineffectiveness [99]. Conflicting data are reported in the literature on the efficacy of etanercept in erythrodermic psoriasis. Campione et al. reported the inefficiency of etanercept in severe erythrodermic psoriasis in 3-year-old Caucasian twins [100]. After informed consent as off-label treatment because of their young age, etanercept was started at a dosage of $0.8 \mathrm{mg} / \mathrm{kg}$ subcutaneously, once a week. It was then stopped for ineffective results, after a total of ten injections [100]. Frega et al., however, reported the case of a 7-year-old patient suffering from erythrodermic psoriasis refractory to cyclosporine and methotrexate, responsive to etanercept [101].

\section{Infliximab}

Infliximab is a chimeric monoclonal antibody that acts by targeting soluble and membrane-bound TNF $\alpha$. It is the only TNF $\alpha$-inhibitor administered by infusion, and it has been FDA approved for the treatment of Crohn's disease in children aged 6 years and older [102, 103]. Based on experience from its administration in adult psoriatic patients, infliximab is associated with a higher risk of infections, tuberculosis reactivation, infusion reactions and congestive heart failure than other TNF $\alpha$ inhibitors, and caution is required with regard to the risk of hepatotoxicity [19].
Data evaluating infliximab use in pediatric psoriasis are lacking. However, sporadic case reports have demonstrated its efficacy for the treatment of recalcitrant, generalized pustular or erythrodermic psoriasis in children after an initial treatment failure with methotrexate, cyclosporine and oral retinoids [37, 104]. Interestingly, only one case reported the successful use of infliximab, in a 9-year-old Caucasian girl with generalized pustular psoriasis, as first-line therapy. The patient received two infliximab infusions $(5 \mathrm{mg} / \mathrm{kg})$ respectively on day 3 and 17 of admission with a rapid clinical improvement of the disease. Infliximab was well tolerated, and no adverse events were registered [105]. Skrabl-Baumgartner et al., however, reported a case of childhood generalized pustular psoriasis responding to infliximab in combination with methotrexate [106].

\section{Adalimumab}

Adalimumab is a monoclonal antibody against TNF $\alpha$. In 2008, the FDA approved adalimumab only for the treatment of children $\geq 6$ years old with ulcerative colitis and Crohn's disease, and the EU granted the marketing authorization for the treatment of juvenile idiopathic arthritis in pediatric patients aged 2 years and older [107]. Nevertheless, several trials evaluating the long-term safety of adalimumab for the treatment of Crohn's disease, ulcerative colitis and uveitis in pediatric patients have been published [108, 109]. Uncomplicated infections and pain reaction of the injection site have been reported as the most common adverse events. Published evidence of adalimumab used in juvenile psoriasis is limited to three case reports in which two pediatric patients with pustular psoriasis, resistant to etanercept and other systemic 
drugs, were successfully treated with adalimumab, at a dose of $40 \mathrm{mg}$ every 2 weeks, while a 9-year-old girl, with a history of acrodermatitis continua of Hallopeau, achieved complete resolution after 8 weeks of treatment with adalimumab [110-112]. Recently, adalimumab was granted marketing authorization in the $\mathrm{EU}$ for severe chronic plaque psoriasis in children aged 4 years and older who have had inadequate response to topical treatments and phototherapy [113].

\section{Ustekinumab}

Ustekinumab is a humanized monoclonal antibody that acts by binding the $\mathrm{p} 40$ protein subunit shared by the IL-12 and IL-23 inflammatory cytokines. Data on the use of ustekinumab for the treatment of pediatric patients are limited. In the literature, there are only three cases of pediatric patients affected by severe plaque psoriasis successfully treated with ustekinumab [114-116]. However, the efficacy and safety of this treatment have recently been evaluated in a multicenter, randomized, double-blind placebo-controlled trial (CADMUS study) in which 110 adolescent patients (aged 12-17 years) were enrolled. Respectively, $78.4 \%$ and $80.6 \%$ of adolescents receiving half-standard dosage $(0.375 \mathrm{mg} / \mathrm{kg})$ and standard dosage $(0.750 \mathrm{mg} / \mathrm{kg})$ achieved PASI75 at 12 weeks as compared with $10.8 \%$ of participants receiving placebo [117].

\section{EMERGING THERAPEUTIC OPTIONS IN THE TREATMENT OF PSORIASIS}

The European Medicines Agency's Committee for Medicinal Products for Human Use (CHMP) has recommended marketing authorization for two drugs for adult psoriasis: secukinumab and apremilast [118, 119]. Secukinumab is a fully human monoclonal antibody that inhibits interleukin 17A. It was recommended for treatment of moderate to severe plaque psoriasis in adults who are candidates for systemic therapy. It is administered by subcutaneous injection [120]. Apremilast, an inhibitor of phosphodiesterase 4 , is indicated for the treatment of adult patients with active psoriatic arthritis or with moderate to severe plaque psoriasis who are candidates for phototherapy or systemic therapy [121]. It is administered orally. There are no case reports or any other studies in the literature investigating the use of these new drugs in pediatric patients.

\section{CONCLUSION}

Psoriasis is a chronic inflammatory skin disease, which is quite common in children. It begins in childhood in almost one-third of the cases, and it is increasing in prevalence and incidence. Therefore, clinicians must maintain a clinical suspicion for the diagnosis of psoriasis at all ages. Even if both topical and systemic therapies are available, pediatric psoriasis treatment may often be challenging mainly because of the absence of standardized guidelines and the very limited evidence-based data from randomized controlled trials. Particularly, the evidence on systemic treatment efficacy and safety is still limited, and long-term data in pediatric patients are lacking so that physicians usually have to rely on published experience from case reports and case series also from other pediatric conditions coming from the disciplines of rheumatology, gastroenterology and oncology. Hence, in everyday practice, clinicians must follow a general approach maximizing the benefit-risk 
ratio (Table 1): the therapeutic choice should be done on a case-by-case basis, with strong consideration of the effect of the disease on the patient and family. Indubitably, more prospective studies and multicenter, international registries are needed to evaluate systemic therapies in pediatric psoriasis to develop international guidelines on pediatric psoriasis treatment.

\section{ACKNOWLEDGMENTS}

No funding or sponsorship was received for this study or publication of this article.

All named authors meet the International Committee of Medical Journal Editors (ICMJE) criteria for authorship for this manuscript, take responsibility for the integrity of the work as a whole and have given final approval for the version to be published.

Disclosures. M. Napolitano, M. Megna, A. Balato, F. Ayala, S. Lembo, A. Villani and N. Balato have nothing to disclose.

Compliance with Ethics Guidelines. This article is based on previously conducted studies and does not involve any new studies of human or animal subjects performed by any of the authors.

Open Access. This article is distributed under the terms of the Creative Commons Attribution-NonCommercial 4.0 International License (http://creativecommons.org/licenses/ by-nc/4.0/), which permits any noncommercial use, distribution, and reproduction in any medium, provided you give appropriate credit to the original author(s) and the source, provide a link to the Creative Commons license, and indicate if changes were made.

\section{REFERENCES}

1. Huerta C, Rivero E, Rodriguez LA. Incidence and risk factors for psoriasis in the general population. Arch Dermatol. 2007;143:1559-65.

2. Megna Matteo, Napolitano Maddalena, Balato A, et al. Psoriasis in children: a review. Curr Pediatr Rev. 2015;11:10-26.

3. Sticherling M, Augustin M, Boehncke WH, et al. Therapy of psoriasis in childhood and adolescence- a German expert consensus. J Dtsch Dermatol Ges. 2011;9:815-23.

4. Tollefson MM, Crowson CS, McEvoy MT, Maradit Kremers H. Incidence of psoriasis in children: a population-based study. J Am Acad Dermatol. 2010;62:979-87.

5. Icen M, Crowson CS, McEvoy MT, Dann FJ, Gabriel SE, Maradit Kremers $H$. Trends in incidence of adult-onset psoriasis over three decades: a population-based study. J Am Acad Dermatol. 2009;60:394-401.

6. Raychaudhuri SP, Gross J. A comparative study of pediatric onset psoriasis with adult onset psoriasis. Pediatr Dermatol. 2000;17:174-8.

7. Farber EM, Nall ML. The natural history of psoriasis in 5,600 patients. Dermatologica. 1974;148:1-18.

8. Christophers E. Comorbidities in psoriasis. Clin Dermatol. 2007;25:529-34.

9. Smith $\mathrm{CH}$, Anstay VA, Barker JN, et al. British Association of Dermatologists' guidelines for biologic interventions for psoriasis 2009. Br J Dermatol. 2009;161:987-1019.

10. Menter A, Korman NJ, Elmets CA, et al. Guidelines of care for the management of psoriasis and psoriatic arthritis: section 6 . Guidelines of care for the treatment of psoriasis and psoriatic arthritis: case-based presentations and evidence-based conclusions. J Am Acad Dermatol. 2011;65:137-74.

11. Fotiadou C, Lazaridou E, Ioannides D. Management of psoriasis in adolescence. Adolesc Health Med Ther. 2014;5:25-34.

12. Cordoro KM. Systemic and light therapies for the management of childhood psoriasis: part II. Skin Therapy Lett. 2008;13:1-3.

13. Holme SA, Anstey AV. Phototherapy and PUVA photochemotherapy in children. Photodermatol Photoimmunol Photomed. 2004;20:69-75. 
14. Coven TR, Burack LH, Gilleaudeau R, Keogh M, Ozawa M, Krueger JG. Narrowband UV-B produces superior clinical and histopathological resolution of moderate-to-severe psoriasis in patients compared with broadband UV-B. Arch Dermatol. 1997;133:1514-22.

15. Lara-Corrales I, Ramnarine S, Lansang P. Treatment of childhood psoriasis with phototherapy and photochemotherapy. Clin Med Insights Pediatr. 2013;7:25-33.

16. Pasic A, Ceovic R, Lipozencic J, et al. Phototherapy in pediatric patients. Pediatr Dermatol. 2003;20:71-7.

17. Dogra S, Kaur I. Childhood psoriasis. Indian J Dermatol Venereol Leprol. 2010;76:357-65.

18. Kopp T, Karlhofer F, Szépfalusi Z, Schneeberger A, Stingl G, Tanew A. Successful use of acitretin in conjunction with narrowband ultraviolet B phototherapy in a child with severe pustular psoriasis, von Zumbusch type. Br J Dermatol. 2004;151:912-6.

19. Marqueling A, Cordoro KM. Systemic treatments for severe pediatric psoriasis: a practical approach. Dermatol Clin. 2013;31:267-88.

20. Pavlovsky M, Baum S, Shpiro D, Pavlovsky L, Pavlotsky F. Narrow band UVB: is it effective and safe for paediatric psoriasis and atopic dermatitis? J Eur Acad Dermatol Venereol. 2011;25:727-9.

21. Wong Y, Koh MJ, Chong WS. Role of narrowband ultraviolet $\mathrm{B}$ phototherapy in the treatment of childhood psoriasis in Asian children. Pediatr Dermatol. 2015;32:e221-3.

22. al-Fouzan AS, Nanda A. UVB phototherapy in childhood psoriasis. Pediatr Dermatol. 1995;12:66.

23. Tay YK, Morelli JG, Weston WL. Experience with UVB phototherapy in children. Pediatr Dermatol. 1996;13:406-9.

24. Jain VK, Aggarwal K, Jain K, Bansal A. Narrow-band UV-B phototherapy in childhood psoriasis. Int J Dermatol. 2007;46:320-2.

25. Zamberk P, Velazquez D, Campos M, Hernanz JM, Lázaro P. Paediatric psoriasis: narrowband UVB treatment. J Eur Acad Dermatol Venereol. 2010;24:415-9.

26. Wolff K. Side-effects of psoralen photochemotherapy (PUVA). Br J Dermatol. 1990;122:117-25.

27. Shah KN. Diagnosis and treatment of pediatric psoriasis: current and future. Am J Clin Dermatol. 2013;14:195-213.
28. Charbit L, Mahé E, Phan A, et al. Systemic treatments in childhood psoriasis: a French multicentre study on 154 children. $\mathrm{Br} J$ Dermatol. 2015. doi:10.1111/bjd.14326. [Epub ahead of print].

29. Zweegers J, de Jong EM, Nijsten TE, et al. Summary of the Dutch S3-guidelines on the treatment of psoriasis 2011. Dermatol Online J. 2014;20:1-112.

30. Lee CS, Koo J. A review of acitretin, a systemic retinoid for the treatment of psoriasis. Expert Opin Pharmacother. 2005;6:1725-34.

31. de Jager ME, de Jong EM, van de Kerkhof PC, Seyger MM. Efficacy and safety of treatments for childhood psoriasis: a systematic literature review. J Am Acad Dermatol. 2010;62:1013-30.

32. Lacour M, Mehta-Nikhar B, Atherton DJ, Harper JI. An appraisal of acitretin therapy in children with inherited disorders of keratinization. $\mathrm{Br} J$ Dermatol. 1996;134:1023-9.

33. Brecher AR, Orlow SJ. Oral retinoid therapy for dermatologic conditions in children and adolescents. J Am Acad Dermatol. 2003;49:171-82.

34. Katugampola RP, Finlay AY. Oral retinoid therapy for disorders of keratinization: single-centre retrospective 25 years' experience on 23 patients. Br J Dermatol. 2006;154:267-76.

35. Halverstam CP, Zeichner J, Lebwohl M. Lack of significant skeletal changes after long-term, low-dose retinoid therapy: case report and review of the literature. J Cutan Med Surg. 2006;10:291-9.

36. Van Dooren-Greebe RJ, Lemmens JA, De Boo T, Hangx NM, Kuijpers AL, Van de Kerkhof PC. Prolonged treatment with oral retinoids in adults: no influence on the frequency and severity of spinal abnormalities. Br J Dermatol. 1996;134:71-6.

37. McMullen EA, McCarron P, Irvine AD, Dolan OM, Allen GE. Association between long-term acitretin therapy and osteoporosis: no evidence of increased risk. Clin Exp Dermatol. 2003;28:307-9.

38. de Oliveira ST, Maragno L, Arnone M, Fonseca Takahashi MD, Romiti R. Generalized pustular psoriasis in childhood. Pediatr Dermatol. 2010;27:349-54.

39. Xiao T, Li B, He CD, Chen HD. Juvenile generalized pustular psoriasis. J Dermatol. 2007;34:573-6.

40. Juanqin G, Zhiqiang C, Zijia H. Evaluation of the effectiveness of childhood generalized pustular psoriasis treatment in 30 cases. Pediatr Dermatol. 1998;15:144-6. 
41. Chao PH, Cheng YW, Chung MY. Generalized pustular psoriasis in a 6-week-old infant. Pediatr Dermatol. 2009;26:352-4.

42. Salleras $M$, Sanchez-Regana $M$, Umbert $P$. Congenital erythrodermic psoriasis: case report and literature review. Pediatr Dermatol. 1995;12:231-4.

43. Judge MR, McDonald A, Black MM. Pustular psoriasis in childhood. Clin Exp Dermatol. 1993;18:97-9.

44. Ergin S, Ersoy-Evans S, Sahin S, Ozkaya O. Acitretin is a safe treatment option for infantile pustular psoriasis. J Dermatol Treat. 2008;19:341-3.

45. Karamfilov T, Wollina U. Juvenile generalized pustular psoriasis. Acta Derm Venereol. 1998;78:220.

46. Liao PB, Rubinson R, Howard R, Sanchez G, Frieden IJ. Annular pustular psoriasis: most common form of pustular psoriasis in children: report of three cases and review of the literature. Pediatr Dermatol. 2002;19:19-25.

47. Warren RB, Chalmers RJ, Griffiths CE, Menter A. Methotrexate for psoriasis in the era of biological therapy. Clin Exp Dermatol. 2008;33:551-4.

48. Paller AS. Dermatologic uses of methotrexate in children: indications and guidelines. Pediatr Dermatol. 1985;2:238-43.

49. Chládek J, Grim J, Martínková J, et al. Pharmacokinetics and pharmacodynamics of low-dose methotrexate in the treatment of psoriasis. Br J Clin Pharmacol. 2002;54:147-56.

50. Wright NA, Piggott CD, Eichenfield LF. The role of biologics and other systemic agents in the treatment of pediatric psoriasis. Semin Cutan Med Surg. 2010;29:20-7.

51. Kalb RE, Strober B, Weinstein G, Lebwohl M. Methotrexate and psoriasis: 2009 National Psoriasis Foundation Consensus Conference. J Am Acad Dermatol. 2009;60:824-37.

52. Ståhle M, Atakan N, Boehncke WH, et al. Juvenile psoriasis and its clinical management: a European expert group consensus. J Dtsch Dermatol Ges. 2010;8:812-8.

53. Gisondi P, Fantuzzi F, Malerba M, Girolomoni G. Folic acid in general medicine and dermatology. J Dermatolog Treat. 2007;18:138-46.

54. Pathirana D, Ormerod AD, Saiag P, Smith C, Spuls PI, Nast A, et al. European S3-guidelines on the systemic treatment of psoriasis vulgaris. J Eur Acad Dermatol Venereol. 2009;23:1-70.
55. Kaur I, Dogra S, De D, Kanwar AJ. Systemic methotrexate treatment in childhood psoriasis: further experience in 24 children from India. Pediatr Dermatol. 2008;25:184-8.

56. van Geel MJ, Mul K, de Jager ME, van de Kerkhof PC, de Jong EM, Seyger MM. Systemic treatments in paediatric psoriasis: a systematic evidence based update. J Eur Acad Dermatol Venereol. 2015;29:425-37.

57. Van Geel MJ, Oostveen AM, Hoppenreijs EP, et al. Methotrexate in pediatric plaque-type psoriasis: long-term daily clinical practice results from the Child-CAPTURE registry. J Dermatol Treat. 2015;20:1-7.

58. Posso-De Los Rios CJ, Pope E, Lara-Corrales I. A systematic review of systemic medications for pustular psoriasis in pediatrics. Pediatr Dermatol. 2014;31:430-9.

59. Juanqin G, Zhiqiang C, Zijia H. Evaluation of the effectiveness of childhood generalized pustular psoriasis treatment in 30 cases. Pediatr Dermatol. 1998;15(2):144-6.

60. Kumar B, Dhar S, Handa S, Kaur I. Methotrexate in childhood psoriasis. Pediatr Dermatol. 1994;11:271-3.

61. Dogra S, Handa S, Kanwar AJ. Methotrexate in severe childhood psoriasis. Pediatr Dermatol. 2004;21:283-4.

62. Dogra S, Kumaran MS, Handa S, Kanwar AJ. Methotrexate for generalized pustular psoriasis in a 2-year-old child. Pediatr Dermatol. 2005;22:85-6.

63. Kalla G, Goyal AM. Juvenile generalized pustular psoriasis. Pediatr Dermatol. 1996;13:45-6.

64. Garg T, Chander R, Mittal S. Familial juvenile generalized pustular psoriasis: response to methotrexate. Skinmed. 2011;9:190-1.

65. Collin B, Vani A, Ogboli M, Moss C. Methotrexate treatment in 13 children with severe plaque psoriasis. Clin Exp Dermatol. 2009;34:295-8.

66. Scott RB, Surana R. Erythrodermic psoriasis in childhood: a young Negro child treated with methotrexate. Am J Dis Child. 1968;116:218-21.

67. Alli N, Góng $\varphi$ r E, Karakayali G, Lenk N, Artóz F. The use of cyclosporin in a child with generalized pustular psoriasis. Br J Dermatol. 1998;139:754-5.

68. Perrett CM, Ilchyshyn A, Berth-Jones J. Cyclosporin in childhood psoriasis. J Dermatolog Treat. 2003;14:113-8. 
69. Pereira TM, Vieira AP, Fernandes JC, Sousa-Basto AJ. Cyclosporin A treatment in severe childhood psoriasis. J Eur Acad Dermatol Venereol. 2006;20:651-6.

70. Kiliç SS, Hacimustafaoğlu M, Celebi S, Karadeniz A, Ildirim I. Low dose cyclosporin A treatment in generalized pustular psoriasis. Pediatr Dermatol. 2001;18:246-8.

71. Mahé E, Bodemer C, Pruszkowski A, Teillac-Hamel $\mathrm{D}$, de Prost Y. Cyclosporine in childhood psoriasis. Arch Dermatol. 2001;137:1532.

72. Koo J. Systemic sequential therapy of psoriasis: a new paradigm for improved therapeutic results. J Am Acad Dermatol. 1999;41:S25-8.

73. Lebwohl M, Ali S. Treatment of psoriasis. Part 2. Systemic therapies. J Am Acad Dermatol. 2001;45:649-61.

74. Ellis CN. Safety issues with cyclosporine. Int J Dermatol. 1997;36:7-10.

75. Kim HS, Kim GM, Kim SY. Two-stage therapy for childhood generalized pustular psoriasis: low-dose cyclosporin for induction and maintenance with acitretin/narrowband ultraviolet B phototherapy. Pediatr Dermatol. 2006;23:306-8.

76. Nakamura S, Hashimoto $\mathrm{Y}$, Igawa $\mathrm{S}$, et al. Childhood generalized pustular psoriasis treated by preprandial ciclosporin administration: serum cytokine pattern during the course of the disease. Clin Exp Dermatol. 2009;34:e1023-4.

77. Bulbul Baskan E, Yazici S, Tunali S, Saricaoglu H. Clinical experience with systemic cyclosporine A treatment in severe childhood psoriasis. J Dermatolog Treat. 2015:1-4 [Epub ahead of print].

78. Di Lernia V, Stingeni L, Boccaletti V, et al. Effectiveness and safety of cyclosporine in pediatric plaque psoriasis: a multicentric retrospective analysis. J Dermatolog Treat. 2015;10:1-4.

79. Ward A, Brogden RN, Heel RC, Speight TM, Avery GS. Etretinate. A review of its pharmacological properties and therapeutic efficacy in psoriasis and other skin disorders. Drugs. 1983;26:9-43.

80. Namba C, Murakami M, Hanakawa $Y$, et al. Infantile generalized pustular psoriasis: successful disease control with intermittent etretinate. J Dermatol. 2014;41:403-6.

81. Shelnitz LS, Esterly NB, Honig PJ. Etretinate therapy for generalized pustular psoriasis in children. Arch Dermatol. 1987;123:230-3.
82. Tay YK, Tham SN. The profile and outcome of pustular psoriasis in Singapore: a report of 28 cases. Int J Dermatol. 1997;36:266-7.

83. Umezawa Y, Mabuch T, Ozawa A. Generalized pustular psoriasis in a child: observation of long-term combination therapy with etretinate and calcipotriol for 16 years. Pediatr Dermatol. 2012;29:206-8.

84. Rosińska D, Wolska H, Jablonska S, Konca I. Etretinate in severe psoriasis of children. Pediatr Dermatol. 1988;5:266-72.

85. Rood MJ, Lavrijsen SP, Huizinga TW. Acitretin-related ossification. J Rheumatol. 2007;34:837-8.

86. Mrowietz U, Asadullah K. Dimethylfumarate for psoriasis: more than a dietary curiosity. Trends Mol Med. 2005;11:43-8.

87. van Geel MJ, van de Kerkhof PC, Oostveen AM, de Jong EM, Seyger MM. Fumaric acid esters in recalcitrant pediatric psoriasis: a prospective, daily clinical practice case series. J Dermatolog Treat. 2016;27:214-20.

88. Balak DM, Oostveen AM, Bousema MT, et al. Effectiveness and safety of fumaric acid esters in children with psoriasis: a retrospective analysis of 14 patients from The Netherlands. Br J Dermatol. 2013;168:1343-7.

89. Reich K, Hartl C, Gambichler T, Zschocke I. Retrospective data collection of psoriasis treatment with fumaric acid esters in children and adolescents in Germany (KIDS FUTURE study). J Dtsch Dermatol Ges. 2016;14:50-7.

90. Steinz K, Gerdes S, Domm S, Mrowietz U. Systemic treatment with fumaric acid esters in six paediatric patients with psoriasis in a psoriasis centre. Dermatology. 2014;229(3):199-204.

91. Nast A, Kopp I, Augustin M, et al. German evidence-based guidelines for the treatment of psoriasis vulgaris (short version). Arch Dermatol Res. 2007;299:111-38.

92. Lynch M, Kirby B, Warren RB. Treating moderate to severe psoriasis-best use of biologics. Expert Rev Clin Immunol. 2014;10:269-79.

93. Sanclemente G, Murphy R, Contreras J, García H, Bonfill Cosp X. Anti-TNF agents for paediatric psoriasis. Cochrane Database Syst Rev. 2015;11:CD010017.

94. Paller AS, Siegfried EC, Langley RG, et al. Etanercept treatment for children and 
adolescents with plaque psoriasis. $\mathrm{N}$ Engl J Med. 2008;358:241-51.

95. Paller AS, Siegfried EC, Eichenfield LF, et al. Long-term etanercept in pediatric patients with plaque psoriasis. J Am Acad Dermatol. 2010;63:762-8.

96. Giannini EH, Ilowite NT, Lovell DJ, et al. Long-term safety and effectiveness of etanercept in children with selected categories of juvenile idiopathic arthritis. Arthritis Rheum. 2009;60:2794-804.

97. European Medicines Agency. Committee for medicinal products for human use (CHMP) Summary of opinion (post authorisation) for Enbrel (etanercept). July 21, 2011. http://www. ema.europa.eu/docs/en_GB/document_library/ Summary_of_opinion/human/000262/WC5001 0924.pdf.

98. Paller AS, Siegfried EC, Langley RG, et al. Long-term safety and efficacy of etanercept in children and adolescents with plaque psoriasis. J Am Acad Dermatol. 2016;74:280-7.

99. Beikert FC, Augustin M, Radtke MA. Etanercept in juvenile psoriasis. Hautarzt. 2012;63:406-10.

100. Campione E, Diluvio L, Terrinoni A, et al. Severe erytrodermic psoriasis in child twins: from clinical-pathological diagnosis to treatment of choice through genetic analyses: two case reports. BMC Res Notes. 2014;7:929.

101. Fraga NA, Paim Mde F, Follador I, et al. Refractory erythrodermic psoriasis in a child with an excellent outcome by using etanercept. An Bras Dermatol. 2011;86:S144-7.

102. Menter MA, Cush JM. Successful treatment of pediatric psoriasis with infliximab. Pediatr Dermatol. 2004;21:87-8.

103. Farnsworth NN, George SJ, Hsu S. Successful use of infliximab following a failed course of etanercept in a pediatric patient. Dermatol Online J. 2005;11:11.

104. Rott S, Kuster RM, Mrowietz U. Successful treatment of severe psoriatic arthritis with infliximab in an 11-year-old child suffering from linear psoriasis along lines of Blaschko. $\mathrm{Br} \mathrm{J}$ Dermatol. 2007;157:191-2.

105. Tsang V, Dvorakova V, Enright F, Gleeson C. Successful use of infliximab as first line treatment for severe childhood generalized pustular psoriasis. J Eur Acad Dermatol Venereol. 2015. (doi:10).
106. Skrabl-Baumgartner A, Weger W, Salmhofer W, et al. Childhood generalized pustular psoriasis: longtime remission with combined infliximab and methotrexate treatment. Pediatr Dermatol. 2015;32(1):13-4.

107. Luu M, Cordoro KM. The evolving role of biologics in the treatment of pediatric psoriasis. Skin Therapy Lett. 2013;18:1-4.

108. Hyams JS, Griffiths A, Markowitz J, et al. Safety and efficacy of adalimumab for moderate to severe Crohn's disease in children. Gastroenterology. 2012;143:365-74.

109. Biester S, Deuter C, Michels H, et al. Adalimumab in the therapy of uveitis in childhood. $\mathrm{Br} \mathrm{J}$ Ophthal. 2007;91:319-24.

110. Callen JP, Jackson JH. Adalimumab effectively controlled recalcitrant generalized pustular psoriasis in an adolescent. J Dermatol Treat. $2005 ; 16: 350-2$.

111. Alvarez AC, Rodriguez-Nevado I, De Argila D, et al. Recalcitrant pustular psoriasis successfully treated with adalimumab. Pediatr Dermatol. 2011;28:195-7.

112. Dini V, Barbanera S, Romanelli M. Efficacy of adalimumab for the treatment of refractory paediatric acrodermatitis continua of hallopeau. Acta Derm Venereol. 2013;93:588-9.

113. http://www.ema.europa.eu/docs/en_GB/document library/EPAR_Product_Information/human/000481/ WC500050870.pdf. Accessed 2 Mar 2016

114. Fotiadou C, Lazaridou E, Giannopoulou C, Ioannides D. Ustekinumab for the treatment of an adolescent patient with recalcitrant plaque psoriasis. Eur J Dermatol. 2011;21:117-8.

115. AbuHilal M, Ho N. Successful treatment of severe psoriasis in an adolescent with ustekinumab. Pediatr Dermatol. 2015;32:377-80.

116. Dixit S, Shumack S, Fischer G. Ustekinumab in the treatment of severe paediatric psoriasis. Aust J Dermatol. 2013;54:147.

117. Landells I, Colleen Marano, Hsu MC, et al. Ustekinumab in adolescent patients age 12 to 17 years with moderate-to-severe plaque psoriasis: results of the randomized phase 3 CADMUS study. J Am Acad Dermatol. 2015;73:594-603.

118. http://www.ema.europa.eu/docs/en_GB/document_ library/EPAR_Summary_for_the_public/human/ 003729/WC500183132.pdf. Accessed 4 Apr 2016 
119. http://www.ema.europa.eu/docs/en_GB/document library/Summary_of_opinion_-_Initial_authorisation/ human/003746/WC500177621.pdf. Accessed 4 Apr 2016

120. Jaleel T, Elmets C, Weinkle A, et al. Secukinumab (AIN-457) for the treatment of Psoriasis. Expert Rev Clin Pharmacol. 2016;9:187-202.
121. Rich $\mathrm{P}$, Gooderham $\mathrm{M}$, Bachelez $\mathrm{H}$, et al. Apremilast, an oral phosphodiesterase 4 inhibitor, in patients with difficult-to-treat nail and scalp psoriasis: results of 2 phase III randomized, controlled trials (ESTEEM 1 and ESTEEM 2). J Am Acad Dermatol. 2016;74:134-42. 